\title{
Applying Cognitive Linguistics to Teaching English Prepositions: A Quasi- Experimental Study
}

\section{Bui Phu Hung}

PhD candidate at Hue College of Foreign Languages, Hue University, Vietnam, ViceDean at Faculty of Foreign Languages, Van Hien University, Vietnam, buiphuhung@yahoo.com

\section{Truong Vien}

Assoc. Prof., Hue College of Foreign Languages - Hue University, Vietnam, truongviensp@gmail.com

\section{Nguyen Ngoc Vu}

Assoc. Prof., Ho Chi Minh City University of Education, Vietnam,vunn@hcmue.edu.vn

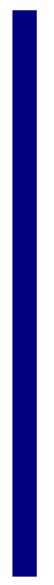

This quasi-experimental study aimed to investigate the effectiveness of applying cognitive linguistics (CL) to teaching English prepositions. The pretest-posttest between-group design was adopted. The participants were selected according to their previous learning experiences, regular out-of-class exposure, eagerness for joining the study, and pretest results. The spatial and metaphorical meanings of the prepositions above, among, at, behind, beside, between, in, in front of, on and under were taught in 4 sessions of 90 minutes. The Cognitive Group received CLbased instructions and the Traditional Group received instructions based on vivid pictures and verbal explanations. The findings showed that the Cognitive Group outperformed the Traditional Group in the posttest in terms of both the spatial and metaphorical meanings. It can be said that CL-based instruction can help learners improve their knowledge of the prepositions better than the traditional pedagogical application. It is recommended that applying cognitive linguistics can help students of other languages master English prepositions. The participants' responses to the questionnaires also assured research reliability and validity.

Keywords: cognitive linguistics, English language teaching, English prepositions, ITPC Model, teaching

\section{INTRODUCTION}

\section{Theoretical background}

The traditional pedagogical options for instructions on English prepositions currently applied in many countries speaking English as a foreign language are mainly based on

Citation: Hung, B. P., Vien, T., \& Vu, N. N. (2018). Applying Cognitive Linguistics to Teaching English Prepositions: A Quasi-Experimental Study. International Journal of Instruction, 11(3), $327-$ 346. https://doi.org/10.12973/iji.2018.11323a 
translation, verbal explanations, and vivid pictures (Hung, 2017 \& Lorincs \& Gordon, 2012). Those in favor of language function classify prepositions according to their functions in language segments, such as prepositions of place, prepositions of time and prepositions of direction and suggest that instruction on prepositions should be based their functions in language segments (Chomsky, 1981 \& Halliday, 2014) and these pedagogical options are also suggested in the textbooks published by international publishers (Hopkins \& Cullen, 2007; Murphy, 2013 \& Oxenden, Latham-Koeing \& Seligson, 2008). These textbooks are used in many countries in the world, including Vietnam. Accordingly, these subtypes of prepositions are taught independently. However, recent studies have shown that these types of instruction do not help students learn and enhance their achievements in English prepositions successfully (Lorincs \& Gordon, 2012). Cho (2010, pp. 267-269) further explains that these types of instruction primarily rest on simple memorization in that they simply learn the target items by heart. In particular, in the study by Cho (2010), the Japanese EFL learners instructed by this pedagogical option improved insignificantly after the treatment. Ausubel (2000) believes that it is crucial to give students opportunities to integrate new input with their existing knowledge as this can help them form a related cognitive structure.

Ticio and Avram (2015) believe that acquisition and learning of an additional language should be somewhat based on its semantic features. It has been widely accepted by language researchers that knowledge of language plays a significant role in production and memory of language. This is especially valid in terms of adult L2 acquisition (Skrzypek \& Singleton, 2013).

The emergence of cognitive linguistics (CL) has implications for teaching prepositions. As CL rests itself against the relationship between the human mind and language, it suggests teaching prepositions should be meaning-based and employ image schemas. Accordingly, humans first experience spatial relation of objects in real life and reflect such a spatial physical relation via linguistic coding (Lee, 2001). The spatial meanings of prepositions can be prototypical and non-prototypical. The following examples by Herskovits (1986) can illustrate this point:

(1) the cat in the house

(2) the flowers in the vase

(3) the bird in the tree

(4) the finger in the ring

The meaning of the preposition in in example 1 is prototypical as the cat as the trajector (the mentioned object) is totally contained in the house as the landmark (the reference entity). However, the trajector (TR) the flowers is not wholly inside the landmark (LM) the vase, which shows that the preposition in in this example has a non-prototypical meaning. In example (3), it is essential to include all the branches of the tree as LM as to use the non-prototypical meaning of the preposition in. In this case, a threedimensional (3-D) space should be construed. In example (4), the finger is conceptualized as TR in a particular position and the ring is construed as LM covering some part of TR. In a word, the preposition in in example (1) is prototypical, while examples (2), (3) and (4) illustrate non-prototypical meanings of the preposition in. 
TR and LM can be illustrated by image schemas which may be 2-dimensional (2-D) or 3-dimensional (Figures $1 \& 2$ ). As can be seen from these figures, TR is contained or inside in LM. "An image schema is a relatively abstract conceptual representation that arises directly from our everyday interaction with and observation of the world around us [and it] derive[s] from sensory and perceptual experience (Evans, 2007, p. 106). When designing the image schema for a preposition, it is important to pay attention to the relationship between the TR and LM, their distance, the presence or absence of contact, shape, and size of TR and LM, and orientation of the trajectory with respect to LM (Taylor, 1989). These criteria help construct the image schemas applied in this study. Herskovits (1986) suggests the image schemas for the preposition in (Figures $1 \&$ 2).

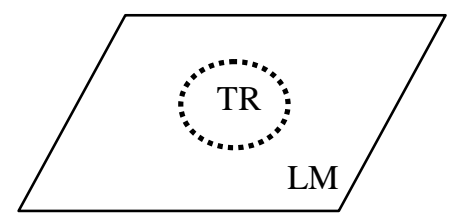

Figure 1

Example of 2-D image schema

Figure 2

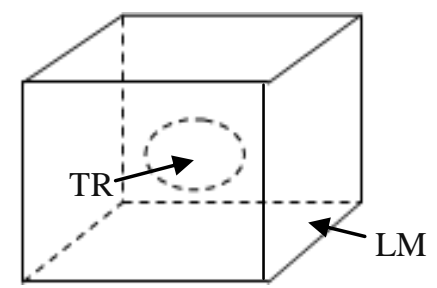

Example of 3-D image schema

To clearly represent the semantics of the ten prepositions, most image schemas applied in this study were 3-D (Figure 3). The image schemas applied this the present study mostly aimed to describe the locations rather than movements. 


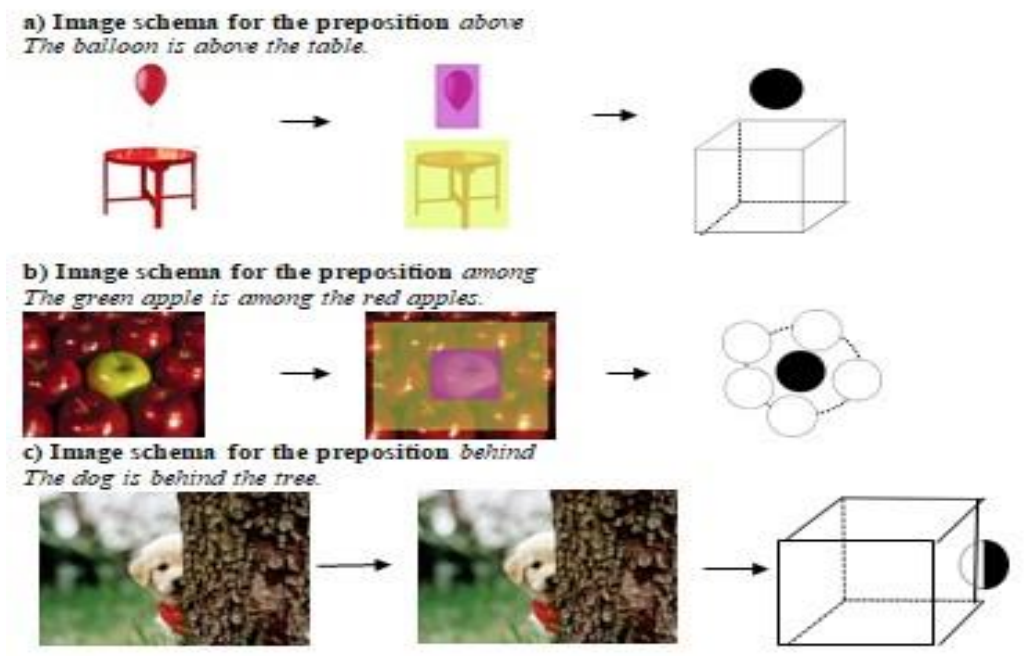

d) Image schema for the preposition beside The man is standing beride the horse.

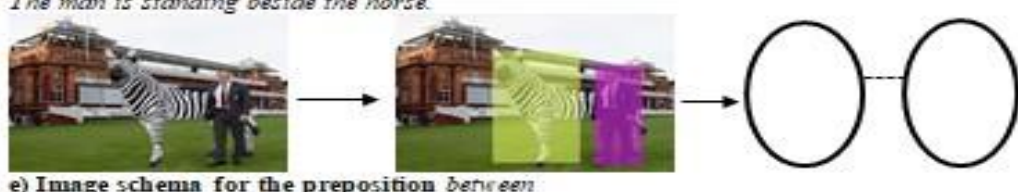

e) Image schema for the preposition betreent

The bench is betreen the trees.

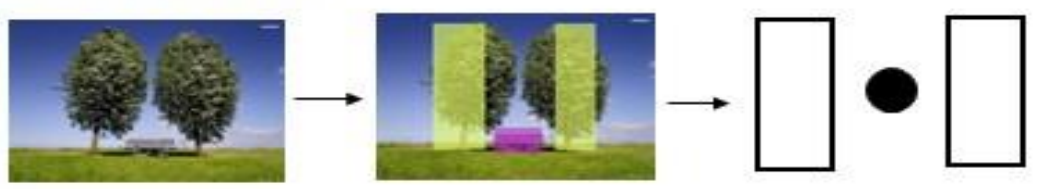

f) Image schema of the preposition on

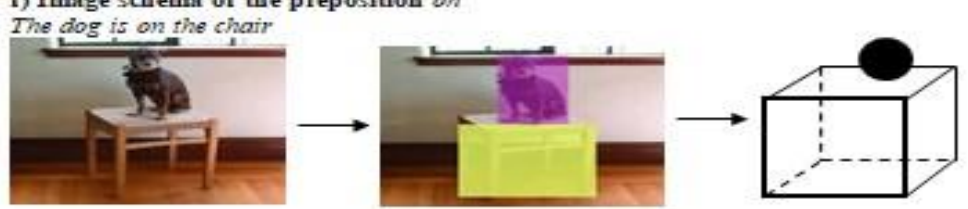

Inage schema for the preposition ivaler The garlic is wader the pillow.
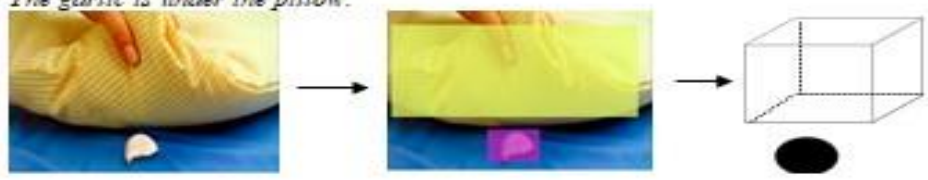

Figure 3

Examples of image schemas for the prepositions in the present study 
Domain Mapping Theory, a basic concept in cognitive linguistics, also postulates the transfer of prepositions across domain in that prepositions can transfer from the spatial domain, where prepositions are used with spatial meanings, to the abstract domain, where conceptual metaphors of prepositions are used. In this case, the spatial domain is the source domain and abstract domain is the target domain. This has aroused an implication that instruction on the metaphorical meanings should activate learners' prior knowledge of the spatial meanings (Figure 4).

Figure 4

\begin{tabular}{|l|l|l|}
\hline Spatial Domain & \multicolumn{1}{|l|}{\begin{tabular}{l} 
Abstract Domain \\
\cline { 1 - 2 } $\begin{array}{l}\text { The director is in his } \\
\text { office. }\end{array}$
\end{tabular}} \\
\hline $\begin{array}{l}\text { There is an apple on } \\
\text { the table. }\end{array}$ & $\longrightarrow \begin{array}{l}\text { You will be in my } \\
\text { heart forever. }\end{array}$ \\
\hline Jane is at the party. & $\begin{array}{l}\text { The plane took off on } \\
\text { schedule. }\end{array}$ \\
$\begin{array}{l}\text { The company is at } \\
\text { risk. }\end{array}$ \\
\hline
\end{tabular}

English prepositions across domains (Adapted from Lee, 2001, pp. 4-23)

Agreeing with Lee (2001), Sobrino (2014) believes that language can transfer from the source domain to metaphorical domain, where certain language items are used with their metaphorical meanings illustrated by image schematic basis "where is a preexistent correspondence between source and target domain". Pérez-Hernández (2011) and Brower (2000) provide many linguistic descriptions of image schemas and domains.

A number of quasi-experimental studies (Bielak and Pawlak, 2013; Boers, 2011; Hung, 2017; Evans and Tyler, 2005; Huong, 2005; Song, Schnotz and Juchem-Grundman, 2015; Tyler, Mueller and Ho, 2011 \& Vasiljevic, 2011) were found relevant references for this study as they applied CL to ELT (English language teaching) in EFL (Englishas-a-foreign-language) con-texts. These studies had things in common. First, inspired by the Theory of Image Schemas, the researchers used symbols to represent semantics of the target items in the form of symbols. Also, explicit formal instruction was applied. Those researchers who attempted to teach conceptual metaphors taught physical spatial meanings first as they are the basic knowledge to make sense of conceptual metaphors. Finally, recent studies inspired by CL approach provoked communicative tasks as they were considered to foster the learners' communication as well as to help them retain the target items (Norris \& Ortega, 2000).

Bielak and Pawlak (2013) experimented CL-based teaching of English tense and aspects. The instructions were explicit and form-focused. The participants were divided into two groups: Cognitive Group receiving CL-based instruction demonstrated by image schemas and symbolic units and Traditional Group receiving instruction accompanied by rules and examples. The Cognitive Group outperformed the Traditional Group in both the immediate posttest and delayed posttest. 
Boers (2011) investigated the effectiveness of CL-based teaching of figurative phrases. His studies employed the Theory of Conceptual Metaphors to teaching phrasal verbs and idioms. As a conclusion, cognitive linguistics shares many facets with applied linguistics. It not only makes an insights into second language acquisition, but it also sets background for English language teaching.

Hung (2017) applied cognitive linguistic approach to teaching the metaphors of the ten English prepositions above, among, at, behind, beside, between, in, in front of, on and under. This study was basically based on the Theory of Image Schemas, Theory of Domains, Theory of Conceptual Metaphors and Usage-based Approach, as basic concepts in cognitive linguistics. An implication was that later studies should have extended to include both the spatial and metaphorical meanings of the prepositions in different contexts.

Evans and Tyler (2005) examined English prepositions in the lens of cognitive linguistics and suggested implications for pedagogical grammar. A conclusion is that the concepts coded in prepositions can be represented by image schemas as this is an inherent feature of prepositions. Also, English prepositions have embodied components related to their spatial meanings. Finally, prepositions in use reflect how humans view the world through spatial and experiential meanings.

Huong (2005) taught English articles to Vietnamese students. The usage-based explicit teacher's instruction was accompaied by image schemas. The participants were divided into two groups for CL-based treatment and traditional treatment, based on verbal explanations. After the study, the cognitive group scored better in the posttest than the traditional group.

Song, et al. (2015) did research comparing the effectiveness of two different treatments: CL-based treatment and traditional pedagogy. The target language included prepositions in, on and at. The CL-based instruction rested itself against the Theory of Domains, Theory of Conceptual Metaphors and ITPC Model; however, the traditional pedagogy was for rote-learning, which was based on simple memorization and verbal explanations. The posttest results showed that the participants receiving CL-based treatment scored higher than those receiving simple verbal definitions of the target items. In addition, the participants got higher scores for metaphorical meanings than spatial meanings of the prepositions.

Tyler et al. (2011) did a quasi-experimental study on applying cognitive linguistics to teaching English prepositions in, on and at. Different from the study by Song et al. (2015), this study did not attempt to explore the participants' growths in the spatial meanings and metaphorical meanings of the prepositions, but it applied the Gestal Learning Theory, which places en emphasis on the relationship between the whole and its parts. In this study, all of meanings of each of the prepositions was taught together in one session. The results were positiive. However, the researchers admitted that the data analysis was relatively simple, basically on the mean scores and standard deviations of the posttest results. 
Vasiljevic (2011) applied the Theory of Conceptual Metaphors and Theory of Domains to teaching idioms to 56 first-year Japanese EFL students at the intermediate level of proficiency. The participants were equally assigned into different groups for different treatments. The groups who received CL-based instructions outperformed the "listing groups", whose learning was based on rote-learning or listings of idioms.

It can be seen from the previous studies applying cognitive linguistics to teaching English prepositions that the study by Tyler et al. (2011) only made a simple data analysis and did not rest on the Domain Mapping Theory. This study was also confined to teaching only three prepositions at, for, and at. The study by Song et al. (2015) did not apply productive tasks (speaking and writing skills) in the class performance. This study attempted to teach only three prepositions in, on, and at. The study by Hung (2017) applied cognitive linguistics to teaching only the metaphors of prepositions and did not rest on the the Domain Mapping Theory.

Although a number of studies had applied CL to ELT, this quasi-experimental study applied innovating applications. Firstly, this study attempted to extend previous studies to teaching ten prepositions above, among, at, behind, beside, between, in, in front of, on and under. Secondly, two tasks for productive skills were delivered after the instruction and forced-choice written exer-cise. Thirdly, this study mostly used 3-D image schemas in representing the semantics of the prepositions, except for the preposition among. In addition, the studies by Song et al. (2015) and Tyler et al. (2011) selected European EFL students as the participants, but this study targeted Vietnamese students. Also, the pretest and posttest applied in this study included an additional text completion section. Last but not least, the study by Song et al. (2015) tested the hypothesis that prepositions could transfer from the spatial domain to the temporal domain and then to the abstract domain. However, this study rested on a hypothesis that the prepositions might transfer from the spatial domain directly to the abstract domain (Evans, 2007, pp. 34-53; Jamrozik \& Gentner, 2011; \& Lakoff \& Johnson, 1980, pp. 30-81).

\section{METHOD}

A university in Ho Chi Minh City, Vietnam, was chosen as the research site as it had conditions facilitating this study. Firstly, the new enrollees, as the target participants, in this institution were required to take only 4 courses in the first semester. Secondly, none of these courses were instructed in English to reduce potential out-of-class exposure. Last but not least, all the students had a portal account so that the researcher could communicate with the students about research-related issues online. It attempted to teach ten English prepositions above, among, at, behind, beside, between, in, in front of, on and under and applied a speaking and a writing task after instruction. Both the spatial and metaphorical meanings of the prepositions were involved.

\section{Research Questions}

1. Is CL-based teaching of the spatial meanings of English prepositions effective in comparison with traditional pedagogical descriptions?

2. Is CL-based teaching of the metaphorical meanings of English prepositions effective in comparison with traditional depagogical descriptions? 


\section{Participants}

50 first-year students from different intact classes at a university in Ho Chi Minh City, Vietnam, were involved in this study. The new enrollees here only needed to take 4 oncampus required courses of 4 hours a week, so they had time to voluntarily attend one of these experimental classes as an additional one and were required to only one EFL course in the first semester and the other courses, as scheduled, were not constructed in English, which partly prevented incomparable exposure to English language during the study. Last but not least, each of the students had an online account registered in the school website, so the researcher could conveniently communicate with the participants about research-related issues. The selected participants gained a score range of 17 to 23 and had a similar experience in English learning and a comparable level of eagerness for joining this study.

Two EFL (English-as-a-foreign-language) teachers with similar teacher characteristics (comparable experience as EFL teachers, a master's degree of English language teaching, English language proficiency and age) volunteered to get involved in the study. Two other EFL teachers working on campus volunteered to assist the researcher in collecting data.

\section{Pilot Study}

Before the pilot study, teacher training was administered and the validity and reliability of the pretest and posttest were explored. After that, linguistic modifications to the tests were made as a result of these participants' feedback that they did not understand some language items. The procedure of the pilot was the same as that of the main study. The participants in the pilot study were not involved in the main study. Information about the participants' out-of-class exposure and unwanted problems that took place during the study and the participants' feedback were also collected. As a result, amendments to the handouts, PowerPoint files and test instruments were made as a result of the participants' responses that some items in the handouts and test instruments did not have sufficient contextual clues and a few language items were unknown to them.

\section{Instructional Treatment}

Each class met once a week, approximately 90 minutes each time, which was based on the relevant previous studies (Song, et al., 2015 \& Tyler, et al, 2011). This study had an interest in applying the integrated text and picture comprehension (ITPC) model (Schnotz, 2005, p. 233) to frame the instruction as it was considered to be suitable for progressive learning and found compatible with the research design (Ausubel, $2000 \&$ Currie, 2008). Song (2013) applied this model in his quasi-experimental study and there were three main class activities: warm-up, instruction with image schemas, and controlled practice. Farías, Obilinovic, Orrego and Gregersen (2014) and Lin (2014) also applied this model in English language teaching experimentals. However, this study added two productive tasks after instruction (Harmer, 2009 \& Norris \& Ortega, 2000). A number of EFL studies inspired from cognitive linguistics had also provided productive tasks in the treatment (Bielak \& Pawlak, 2013; Condon, 2002; Hama, 2005 \& Tyler et al., 2011).

The traditional instruction was explicit and inductive. The pedagogical options for 
teaching prepositions suggested in textbooks published by international publishers were used to design the instructions that the spatial meanings of English prepositions were presented in form of real life pictures and/or verbal explanations (Hopkins \& Cullen., 2013; Murphy, 2013 \& Oxenden, Latham-Koeing \& Seligson, 2008). At the moment, these textbooks were used in many countries in the world and particularly at institution of higher education which was chosen as the research site in this study.

In particular, there were five main activities: (1) warm-up, (2) instruction, (3) gap-filling written exercise, (4) speaking task and (5) writing task. The main difference in teaching spatial and metaphorical meanings was in the activities 1 and 2. In particular, in teaching spatial meanings, students were first provided with five pictures to activate the participants' existing knowledge of prepositions learned in high school. Then, explicit instruction was delivered in compa-ny with the PowerPoint files. The partici-pants were required to match five real life pictures with the meanings presented. However, in teaching the metaphorical meanings, the warm-up activity asked the participants to fill out five sentences with the five prepositions provided. Then, the meanings of each preposition were presented in company with examples one by another and then asked the participants to make examples right after the instruction in each preposition.

The CL-based instruction was also explicit and inductive. The teacher related the spatial and metaphorical meanings by using the same image schemas. In other words, meaningful learning was accommodated in hope that the participants had an opportunity to form a long-term systematic memory. Also, the instruction was meaning-based in assistance of image schemas. The same pictures and exercises used in the traditional treatment were applied to COG.

There were also five main activities as in the traditional treatment. The main dif-ference in teaching the spatial meanings and metaphorical meanings was in the warm-up activity and teacher-fronted instruction. More specifically, in lessons of spatial meanings, the participants were required to gap-fill five sentences depicting five pictures given. The answers to these questions were given in the form of image schemas. In activity 2, each preposition was instructed with three examples, each of which was illustrated by a reallife picture directing to the image schema, which focused on the relation between TR and LM in hope that the partic-ipants could generalize the semantics of the preposition. CL-based teaching of the met-aphorical meanings was related the new input to the participants' existing knowledge. The teacher first delivered a review session in which image schemas of the prepositions to teach were displayed together with exam-ples of their spatial meanings. Secondly, instruction on metaphorical meanings of the prepositions was given by the teacher. Each preposition was presented with three examples leading the participants to the same image schema used in the lessons of spatial meanings.

\section{Pretest and Posttest}

As this study aimed to figure out the effects of the treatment on students' knowledge of the prepositions, indirect pretest pretest and posttest were used (Harmer, 2007, p. 168 \& 2009, p. 323). Discrete-point tests were included as they focused on individual specific language items (Bassili, Smith \& MacLeod, 1989; Graf \& Mandler, 1984 \& Graf \& 
Schacter, 1985). However, this type of test may distract learners by moving from item to item (Harmer, 2007, pp. 168-170 \& Ellis, 2008). A text-completion format was added as it might reflect the participants' understanding of context of the text (Harmer, 2009, p. 324). Concerning the content, all the test items contained authentic language and were at a comparable level of difficulty.

Each of the tests contained three main sections: forced-choice sentence completion section, multiple choice question section and text completion section, each of which consisted of 20 questions: 10 items about spatial meanings ( 1 item/1 preposition) and the other 10 items about metaphorical meanings ( 1 item/1 preposition).

\section{FINDINGS}

The collected data were input into SPSS for computation. Mean scores, standard deviation (SD), significance level, Cronbach's alpha, and independent samples t-test were used to measure the participants' improvements in understanding the seman-tics of the prepositions as well as to assure research reliability and validity. Table 1 shows the total mean scores COG and TRAD achieved in the pretest and posttest. Overall, although both groups got a relatively comparable score in the pretest, COG outperformed TRAD in the posttest. In particular, COG improved by 6.96 points from the pretest to the posttest, but TRAD's mean score increased by only 2.08 points. It can be seen that COG's total gain (score improvement from the pretest to posttest) was three times as high as that of TRAD. Also, the standard deviations show that individuals in both groups had their data points equally close to the mean, but these values dispersed after the treatments. More specifically, the standard deviations for COG and TRAD were 4.243 and 3.796 repsectively. That means, some COG members gained more than their counterparts.

Table 1

Total gains by COG and TRAD

\begin{tabular}{lcccc}
\hline & \multicolumn{2}{c}{ COG $(\mathrm{n}=25)$} & \multicolumn{2}{c}{ TRAD $(\mathrm{n}=25)$} \\
\hline & Mean & SD & Mean & SD \\
\hline Pretest & 20.04 & 2.15 & 20.28 & 2.15 \\
\hline Posttest & 27.00 & 4.24 & 22.34 & 3.80 \\
\hline Gain & 6.96 & 2.85 & 2.06 & 2.47 \\
\hline
\end{tabular}

The statistical analysis also shows that there were more improvements in spatial meanings than metaphorical meanings from the pretest to the posttest (Tables 2 and 3). In general, COG's mean scores in both spatial and metaphorical meanings grew more than those of TRAD. As can be seen from Table 2, the mean score in the spatial meanings which TRAD achieved in the pretest was slightly higher than that of COG and individual scores were closer to the mean. However, COG's mean score developed substantially (4.36 points), but TRAD achieved only a marginally higher mean score in the posttest (0.24 points). Also, the standard deviations indicate that COG's data points in the posttest spread out over a wider range of values than those of TRAD. Both COG's and TRAD' mean scores in metaphorical meanings improved slightly from the pretest to the posttest. Although TRAD got a slightly higher mean score than COG in the pretest, COG's mean score grew slightly higher than that of TRAD in the posttest, at 2.60 points and 1.84 points respectively. 
Table 2

Gains in spatial meanings

\begin{tabular}{lllll}
\hline & COG & & TRAD & \\
\hline & Mean & SD & Mean & SD \\
\hline Pretest & 12.68 & 2.30 & 12.80 & 1.96 \\
\hline Posttest & 17.08 & 2.85 & 13.04 & 2.37 \\
\hline Gain & 4.36 & 2.14 & 0.24 & 1.90
\end{tabular}

Table 3

Gains in metaphorical meanings

\begin{tabular}{lllll}
\hline & COG & \multicolumn{3}{c}{ TRAD } \\
\hline & Mean & SD & Mean & SD \\
\hline Pretest & 7.36 & 1.44 & 7.48 & 1.74 \\
\hline Posttest & 9.96 & 2.82 & 9.32 & 3.11 \\
\hline Gain & 2.60 & 1.58 & 1.84 & 2.78 \\
\hline
\end{tabular}

The score improvements made by COG and TRAD individual members (Table 4) were kept anonymous and numbered 1-25. Overall, the score gain among COG participants varied from 2 to 14 , but that ranged from 0 to 10 in TRAD. As can be seen from Table 4, 18 out of 25 COG par-ticipants achieved over 6 points. 14 out of these 18 individuals gained from 6-10 points and the other 4 participants gained over 10 points. However, only 2 out of 25 TRAD participants gained over 6 points. Also, 5 out of 25 COG participants gained less than 4 points, but 22 TRAD participants were within this range. In addition, all COG par-ticipants made gains in knowledge of the semantics of prepositions. Nonetheless, 7 out of 25 TRAD participants made no gains from the pretest to the posttest. In brief, the cognitive treatment had more positive effects on the participants' knowledge of the meanings of the prepositions than the traditional treatment.

Table 4

Individual score gains

\begin{tabular}{lllllll}
\hline No. & \multicolumn{1}{l}{ TRAD } & \multicolumn{3}{c}{ COG } \\
\hline 1 & Pre & Post & Gain & Pre & Post & Gain \\
\hline 2 & 19 & 19 & 0 & 20 & 25 & 5 \\
\hline 3 & 21 & 22 & 1 & 19 & 26 & 7 \\
\hline 4 & 18 & 19 & 1 & 20 & 27 & 7 \\
\hline 5 & 21 & 21 & 0 & 22 & 31 & 9 \\
\hline 6 & 23 & 27 & 4 & 21 & 27 & 6 \\
\hline 7 & 22 & 22 & 0 & 23 & 37 & 14 \\
\hline 8 & 22 & 23 & 1 & 22 & 28 & 6 \\
\hline 9 & 23 & 24 & 1 & 19 & 22 & 3 \\
\hline 10 & 20 & 22 & 2 & 17 & 23 & 6 \\
\hline 11 & 23 & 25 & 2 & 18 & 26 & 8 \\
\hline 12 & 23 & 28 & 5 & 17 & 24 & 7 \\
\hline 13 & 19 & 21 & 2 & 17 & 21 & 4 \\
\hline 14 & 17 & 18 & 1 & 21 & 25 & 4 \\
\hline 15 & 20 & 20 & 1 & 17 & 19 & 2 \\
\hline 16 & 18 & 18 & 0 & 20 & 28 & 8 \\
\hline & & & & & &
\end{tabular}




\begin{tabular}{lllllll}
\hline 17 & 21 & 22 & 1 & 18 & 29 & 11 \\
\hline 18 & 17 & 20 & 3 & 19 & 24 & 5 \\
\hline 19 & 18 & 18 & 0 & 21 & 27 & 6 \\
\hline 20 & 23 & 30 & 7 & 23 & 35 & 12 \\
\hline 21 & 19 & 19 & 0 & 23 & 31 & 8 \\
\hline 22 & 22 & 23 & 1 & 22 & 26 & 4 \\
\hline 23 & 23 & 33 & 10 & 22 & 28 & 6 \\
\hline 24 & 17 & 21 & 4 & 23 & 34 & 11 \\
\hline 25 & 19 & 21 & 2 & 17 & 24 & 7 \\
\hline
\end{tabular}

Paired samples t-test between the pretest and posttest across Cognitive Group (COG) and Traditional Group (TRAD) shows that COG's mean scores for the whole tests, spatial meanings and metaphorical meanings were significant (Table 5). In detail, COG's improvements in terms of the whole test, spatial meanings and metaphorical meanings were significant, but TRAD's score improvement in metaphorical meanings was insignificant.

Table 5

Paired samples correlation

\begin{tabular}{lllll}
\hline \multicolumn{3}{c}{ Correlation } & Sig. \\
\hline$(\mathrm{n}=25)$ & COG & TRAD & COG & TRAD \\
\hline Total score & .795 & .794 & .000 & .000 \\
\hline Spatial & .675 & .630 & .000 & .001 \\
\hline Metaphorical & .727 & .458 & .000 & .021 \\
\hline
\end{tabular}

The Independent Samples t-test across the three sections in the pretest and posttest respectively between the two groups indicates that there was no significant difference between both groups' scores in the pretest, including the total scores and scores for all the three sections $(p>0.1)$. There was a relatively considerable increase in COG's scores for all the three sections: Sentence Completion (SC), Multiple Choice (MC) and Text Completion (TC). The Independent Samples $t$-Test of COG's scores shows that its gains were significant $(p<0.001)$. On contrary, the Independent Samples $t$-test of TRAD' scores shows that its gains were insignificant. In particular, the $p$ values for its score increase for SC, MC and TC each were higher than 0.05 and TC was the section in which TRAD members made the least increase of all. There were significant differences in COG's scores for the pretest and posttest. On average, its posttest score as a whole was nearly 7 points higher than that of the pretest. However, this figure of TRAD was only about 3 points. Finally, COG's average score differences in the three sections between the pretest and posttest varied within the range of 2 points, but these figures of TRAD were only around 1 point. These differences were also demonstrated by the paired $t$-test statistics ( $t$ value). Cronbach's alphas show that the output for both groups were statistically valid ( $\alpha=0.847$ for COG and $\alpha=0.728$ for TRAD).

The comparison of the mean scores of the three different sections of the test made by the two groups (Table 6) shows a breakdown of both experimental groups' scores of the pretest, posttest, and gain by test section. As can be seen, both groups' mean scores for each of the three sections improved to a certain extent. First of all, both groups got the 
highest scores for the Multiple Choice Section (higher than 10 points) and lowest scores for Text Comple-tion Section. Also, COG's score improvement for each section was within the range of 2.4 points and 2.48 points, but TRAD's gain score for each section was lower than 1 point. Finally, although COG got a marginally lower score for Sentence Completion Section of the pretest than TRAD, its score for this section was considerably higher than that of TRAD in the posttest.

Table 6

Mean scores in 3 test sections

\begin{tabular}{llllll}
\hline Section & \multicolumn{3}{c}{ Mean } & \multicolumn{3}{c}{ SD } \\
\hline \multirow{3}{*}{ SC } & & COG & TRAD & COG & TRAD \\
\hline \multirow{3}{*}{ MC } & Pre & 5.40 & 5.96 & 1.658 & 1.338 \\
\cline { 2 - 6 } & Post & 7.84 & 6.76 & 1.818 & 1.615 \\
\cline { 2 - 6 } & Gain & 2.44 & .80 & 1.212 & 1.555 \\
\hline \multirow{3}{*}{ TC } & Pre & 10.48 & 10.28 & 1.759 & 1.308 \\
\cline { 2 - 6 } & Post & 12.96 & 11.04 & 2.131 & 2.336 \\
\cline { 2 - 6 } & Gain & 2.48 & .76 & 1.327 & 1.809 \\
\hline & Pre & 4.16 & 4.04 & 1.519 & 1.369 \\
\hline & Post & 6.20 & 4.56 & 1.756 & 1.710 \\
\cline { 2 - 6 } & Gain & 2.04 & .52 & 1.399 & 1.636 \\
\hline
\end{tabular}

In summary, the analysis demonstrates that Cronbach's alpha $(\alpha)$ was higher than 0.7 and a paired samples test within COG showed that it was significant, $\mathrm{p}<0.05$ and the correlation between the pretest and posttest was higher than 0.79. The correla-tion between the pretest and posttest in terms of spatial meanings and metaphorical meanings was higher than 0.60 and higher than 0.45 respectively. The independent sample t-test also showed that the equality of means was significant, $p<0.05$. As in the aforementioned discussion, CL-based teaching helped the participants improve their understanding of both spatial and metaphorical meanings of the prepositions. However, the findings showed the cognitive treatment was more valid in teaching the spatial meanings than metaphorical meanings. COG participants' gains were considerable in comparison with previous studies probably because of the application of productive tasks after instruction.

\section{DISCUSSION}

At this point, it is possible to preliminarily address the first research question of this present study. The foregoing analyses indicate that it may be, at least, moderately effective to apply CL-based teaching. It is important to know that the main difference in the cognitive and traditional types of treatment was in the instruction. In other words, COG's score improvement was mainly tailored to the pedagogical CL-based instruction. The results of the entire testing instrument set were briefly discussed right in the analyses of the findings.

Firstly, it can be seen that there were significant improvements in COG's scores from the pretest to posttest, illustrated by the statistically significant difference between the scores of this group and those between the two groups in terms of the total scores, scores for the spatial meanings and scores for the metaphorical meanings. It should be also 
added that there were no statistically significant differences over time in the scores of TRAD. In fact, what appears from these analyses that both kinds of treatment had a pronounced impact on the scores of both groups involved in this study, resulting in their statistical score growth from the pretest to the posttest. Secondly, in contrast to TRAD, COG developed significantly in terms of their knowledge and retaining the semantics of the prepositions, leading to their improvements in their scores. In particular, COG's mean scores for the spatial meanings and metaphorical meanings rose by 4.36 and 2.60 respectively, but those of TRAD rose by only 0.24 and 1.84 . That is, COG improved more significantly in their knowledge of both types of meanings than TRAD. Interestingly, with the instructions accompanied by image schemas, COG participants displayed higher achievements in the posttest. However, an arising question may be about why COG made higher achievements in understanding the spatial than metaphorical meanings. It is important to know that image schemas originated from the spatial domain or source domain. Cognitive linguists believe that people perceive and are able to use the spatial meanings of prepositions from their daily life and construct image schemas in mind before they are able to use their conceptual metaphors through domain transfer. In other words, image schemas are more closely and directly associated with spatial meanings than metaphorical meanings of prepositions (Evans \& Green, 2006). Moreover, Kemmerer (2005) believes that applying Domain Mapping Theory to teaching English prepositions is an alternative; however, other pedagogical options may also work as the different semantic types of English prepositions can be taught and learned separately. Kemmerer (2005) further explains that participants can score higher for one type of meanings than another. In addition, COG's and TRAD's achievements in all the three sections were somewhat paralleled and were of a similar pattern. They both gained higher scores for gap-filling and multiple choice questions than text completion. This may have been because the answers to multiple choice questions were easier to guess from the choices given and text completion re-quired the participants' understanding of the context of the whole text (McAllister \& Guidice, 2012). What is more, the participants scored higher in the usage-based sections (sentence completion and multiple choice) in both the pretest and posttest. An explanation may be that cognitive linguistics is a usage-based approach; that means, it directs the learners more to knowledge and understanding of the meanings of prepositions than using them and the applied instructions were also rather usage-based (Evans \& Green, 2006, p. 3).

Regarding individual participants' score increase (Figure 2 and Figure 3), there would be inter-subject and intra-subject var-iability. It is clear from the investigation into the two bar charts that COG members, in general, scored higher than those of TRAD in the posttest. The number of COG members improving by 10 points and higher was 4 , but only one member of TRAD could get this score development. Also, seven members of TRAD did not improve throughout the treatment, but this occasion did not occurred among COG members. The disper-sion data may confirm that individual par-ticipants would be affected by the treatment in disparate ways. This conclusion was supported by the standard deviations for the entire test. However, an arising question may be about why members of the same group improved differently although they received the same 
treatment. The pattern emerging from the analysis of inter-subject variability may have been due to inter-group differences.

The analysis of inter-group differences (from the pre-questionnaire) revealed interesting data about the learner variables. First, all the participants responded that they experienced a comparable amount of learning English and one of them received instructions accompanied by image schemas. The most common type of instruction they had received was based on vivid pictures. The other types of instruction, including sentence examples, memorization and translation were also common responses. All participants made more than one answer option. The participants having received these types of instruction were divided into both COG and TRAD. The number of both groups' participants who had a low level of motivation but gained significantly from the study were just minor, whose initials were Mr. NHMN (COG 17), Mr. NTH (COG 19), Mr. NCN (TRAD 20) and Mr. BTH (TRAD 21).

A qualitative analysis of the participants' responses to the post-questionnaires also confirmed the research validity and re-liability in term of learners' exposure to Eng-lish language. Most of the participants re-sponded that they did not have any extra exposure outside the classroom. In fact, two participants Mr. NPAT (COG 5) and Mr. NHT (COG 23) watched a 20-to-30-minute part of an American film which was dubbed into Vietnamese and which had no English subtitle. Mr. TLN (C 1), Mr. NHD (C 2) and Mr. LLT (C 15) responded that they saw pop-up advertisements in English, but they ignored them. Two TRAD participants called Ms. NNPT (T 3) and Ms. DTNP (T 25) revealed that they each accidentally had a conversation with a foreigner for about 2-5 minutes. Mr. VTDT (T 1) and Ms. DTHT (T 6) responded that they saw pop-up adver-tisements, but they did not pay attention. Ms. PTTM (T 14) revealed he went to an English speaking club for 30 minutes, but he did not participate. Mr. LCN (T 20) said that he watched an American movie dubbed into Vietnamese for 90 minutes. The results show that TRAD members were more slightly ex-posed to English language during the study, yet scored lower than COG as both groups did not really pay attention. Their exposure to English language was inconsiderable and did not significantly contribute to the improvement in their test scores.

There may have been some other factors that influenced the participants' test scores during the treatment, one concern of which may be the participants' types of intelligence. However, it may take years to identify learners' type of intelligence (Gardner, 2006 \& Fasko, 2001). It has to be remembered, though, that types of learning intelligences do not directly translate into participants' score development in a short run (Bielak \& Pawlak, 2013).

A comparison between the findings of this study and those of previous studies showed interesting implications. The findings of this study confirmed a study by Song, et al. (2015) in that they showed both groups' growths in their scores for both spatial and metaphorical meanings. In fact, COG considerably outperformed TRAD in term of understanding of spatial meanings in the posttest, but there was only a minor dif-ference in the improvements of their knowledge of the metaphorical meanings. However, the study by Song, et al. (2015) admitted that COG and TRAD improved less than the two 
groups involved in this present study. In the former study, the scores achieved by COG and TRAD totally rose by 3.32 points and 0.81 points respectively. COG's score for the spatial meanings and metaphorical meanings developed by 1.01 points and 1.74 points respectively, but TRAD lost 0.04 point for the spatial meanings and gained 1.18 point for the metaphorical meanings. An explanation for this difference may have been in the pedagogical applications in that there was no evidence that the former study applied these post-teaching activities. Lee (2003), Nagy and Scott (2000), Schmitt (2008) and Shintani (2011) assert that these post-teaching activities could contribute to learners' retention of the target items.

Also, this study generally confirmed the study by Tyler, et al. (2011). In the previous study by Tyler et al. (2011), COG gained 4.9 points on average. Only one participant lost one point and the other participants generally made significant gains. However, the data analysis, as admit-ted by the researchers, was relatively simple. There were no discussions on gains in different semantic facets of the prepositions. It was hard to make further comparisons between the findings from these two studies.

\section{CONCLUSION}

The present study aimed to investigate the effectiveness of applying CL-based ap-proach to teaching both spatial and meta-phorical meanings of prepositions. The study also compared the findings from the CL-based instructional description and tra-ditional instructional description. The findings from this study were in line with local and international studies of applying this approach (Hung, 2017; Huong, 2005; Song et al., 2015 \& Tyler et al. 2011). CL-based approach provided L2 learners with signifi-cant understandings of the spatial and met-aphorical meanings of prepositions. After CLbased instructions of totally 6 hours, the participants showed considerable gains, with the assistance of visual aids mainly from the PowerPoint files.

The participants' responses to the questionnaire illustrated that COG and TRAD generally had comparable out-of-class exposure during the study. More specifically, one of them remained free from extra courses in English. They did not watch movies in English nor converse with for-eigners in English as they believed they were not proficient enough for that. Three participants from COG and five participants from TRAD watched American films dubbed into Vietnamese, and they did not pay attention to English subtitles at all. They did not join any website written in English during the study. All of them also revealed that each participant reviewed the lesson from 20 to 30 minutes each week.

The statistical analysis shows that the study gave more positive findings than the previous studies (Song et al., 2015). This may have been caused by the participants' additional practices of productive skills after instruction. In addition, the use of image schemas in instructing spatial and metaphor-ical meanings of prepositions was valid. The prepositions had opportunities to transfer from the spatial domain to the abstract domain via the use of image schemas.

However, the research population was quite limited. Also, the exploration into sub-ject interferences with the findings were based on the learners' responses. Finally, cognitive 
linguistics was a usage-based ap-proach (Evans \& Green, 2006). In other words, language fluency was not a focus of the treatment. Although the participants were involved in productive tasks, the teacher-fronted time was the main input. This was also reflected in the measures of the pretest and posttest, which was in the form of direct tests.

These participants were first-year students who already learned prepositions in traditional approach in high school and the pretest and posttest contained simple vocabulary and clues for them to choose the right answers. The application should be extended in different contexts to know to what extent this approach is valid.

This article provides an insight into the effectiveness of applying cognitive linguistic approach to Eng-lish language teaching and its pedagogical applications give implications for practices and studies (Langacker, 2008, p.66). There should be more experimental studies apply-ing cognitive linguistics to ELT. The unex-plored areas of the application of cognitive linguistics can be endeavors to ELT researchers and practitioners. Future studies applying cognitive linguistics in different contexts can provide better insights into its range of applications in ELT.

\section{REFERENCES}

Ausubel, D. P. (2000). The acquisition and retention of knowledge: a cognitive view. Boston: Kluwer Academic Publishers.

Bassili, J. N., Smith, M. C. \& MacLeod, C. M. (1989). Auditory and visual word-stem completion: separating data driven and conceptuallly driven processing. The Quaterly Journal of Experimental Psychology, 41A (3), 439-453. https://doi.org/10.1080/14640748908402375

Bielak, J. \& Pawlak, M. (2013). Applying cognitive grammar in the foreign language classroom: Teaching English tense and aspect. Kalisz, Poland: Springer.

Boers, F. (2011). Cognitive semantic ways of teaching figurative phrases: an assessment. Review of Cognitive Linguistics 9(1), 227-261. https://doi.org/10.1075/rcl.9.1.11be

Brower, C. (2000). A cognitive theory of musical meaning. Journal of Music Theory 44 (2), 323-379. https://doi.org/ 10.2307/3090681.

Cho, K. (2010). Fostering the acquisition of English prepositions by Japanese learners with networks and prototypes. In S. D. Knop, F. Boers \& A. D. Rycker (Eds.), Fostering language teaching efficiency through cognitive linguistics (pp. 259-275). Berlin: Mouton de Gruyter.

Condon, N. (2002). A cognitive approach to phrasal verbs: How useful is it?". IVACS Conference: University of Limerick, Ireland.

Currie, Q. T. (2008). Animation as reality: factors impacting cognitive load in studiobased E-learning. Unpublished Doctoral dissertation, Capella University. Retrieved 
from https://search.proquest.com/openview/d7ef7a6c9139610f8c36d7a0bf1b1909/1?pqorigsite $=$ gscholar $\& \mathrm{cbl}=18750 \&$ diss $=\mathrm{y}$

Ellis, R. (2008). Investigating grammatical difficulty in second language learning: Implications for second language acquisition research and language testing". International Journal of Applied Linguistics, 18, 4-22. https://doi.org/ 10.1111/j.14734192.2008.00184.x.

Evans, V. (2007). A glossary of cognitive linguistics. Utah: University of Utah Press.

Evans, V. \& Green, M. (2006). Cognitive linguistics. An introduction. Edinburgh: Edinburgh University Press.

Evans, V. \& Tyler, A. (2005). Applying cognitive linguistics to pedagogical grammar: the English prepositions of verticality. Revista Brasileira de Linguística Aplicada, 5(2), 11-42. http://dx.doi.org/10.1590/S1984-6398 2005000200002

Farías, M., Obilinovic, K., Orrego, R. \& Gregersen, T. 2014. Evaluating types and combinations of multimodal presentations in the retention and trasnfer of concrete vocabulary in EFL learning. Revista Signos. Estudios de Lingũistica 47(83), 21-39. https://doi.org/ 10.4067/S0718-09342014000100002.

Fasko, D. (2001). Education and creativity. Creativity Research Journal, 13(3), 317327. https://doi.org/10.1207/S15326934CRJ1334_09

Gardner, H. (2006). Multiple intelligences: New horizons. New York: Basic Books.

Grafs, P. \& Mandler, G. (1984). Activation makes words more assessible, but not necessary more retrievable. Journal of Verbal Learning and Verbal Behavior, 23, 553568 .

Grafs, P. \& Schacter, D. (1985). Implicit and explicit memory for new associations in normal and amnesic subjects. Journal of Experimental Psychology: Learning, Memory and Cognition, 11, 501-518. http://psycnet.apa.org/buy/1986-12203-001

Hama, M. (2005). The effects of the minilesson on advanced learners'acquisition of English modals: A case study". Unpublished manuscript, Department of Linguistics, Georgetown University, Washington, D. C., 2005. In A. Tyler. Cognitive linguistics and second language learning: Theoretical basics and experimental evidence. New York: Rouledge.

Harmer, J. (2007). How to Teach English. Essex, England: Pearson Education.

Harmer, J. (2009). The practice of English language teaching. Essex, England: Pearson Education.

Herskovits, A. (1986). Language and spatial cognition - an interdisciplinary study for the perceptions in English. Cambridge, UK: Cambridge University Press.

Hopkins, D. \& Cullen, P. (2007). Grammar for IELTS with answers: Self-study grammar, reference and practice. Cambridge: Cambridge University Press. 
Hung, B. P. (2017). Vietnamese students learning the semantics of English prepositions. GEMA Online ${ }^{@}$ Journal of Language Studies, 17(4), 14-27. http://doi.org/10.17576/gema-2017- 1704-10

Huong, N. T. (2005). Vietnamese learners mastering English articles. Unpublished doctoral dissertation, University of Groningen. Retrieved from https://www.rug.nl/ research/portal/files/2925151/c8.pdf

Jamrozik, A. \& Gentner, D. (2011). Prepositions in and on retain aspects of spatial meaning in abstract contexts. Proceedings of the 33rd Annual Meeting of the Cognitive Science Society, 1589-1594.https://escholarship. org/uc/item/0kd5r1db

Kemmerer, D. (2005). The spatial and temporal meanings of English prepositions can be independently impaired. Neuropsychologia, 43(5), 797-806. https://doi.org/10.1016/j. neuropsychologia.2004.06.025

Lakoff, G. \& Johnson, M. (1980). Metaphors we live by. Chicago: Chicago University Press.

Langacker, R. W. (2008). Cognitive grammar: A basic introduction. Oxford: Oxford University Press.

Lee, D. (2001). Cognitive linguistics: An introduction. New York: Oxford University Press.

Lin, Lu-Fang. (2014). Chinese-speaking learners' cognitive comprehension problems with English video-based materials. Journal of Educational Computing Research, 51(1): 23-47. https://doi.org/10.2190/EC.51.1.b

Lorincs, K. \& Gordon, R. (2012). Difficulties in learning prepositions and possible solutions. Linguistics Portfolios, 1, Article 14.Retrieved from http://repository.stcloudstate.edu/stcloud_ling/vol1/iss1/14/

McAllister, D. \& Guidice, R. M. (2012). This is only a test: A machine-graded improvement to the multiplechoice and true-false examination. Teaching in Higher Education, 17(2), 193-207. https://doi.org/10.1080/13562517.2 011.611868

Murphy, R. (2013). English grammar in use (3rd ed.). Cambridge: Cambridge University Press.

Nagy, W. E. \& Scott, J. A. (2000). Vocabulary processes. In: Kamil, M. L., Mosenthal, P. B., Pearson, P. D. \& Barr, R. Handbook of reading research, Vol 3 (pp. 269-284). Mahwah, NJ: Erlbaum.

Norris, J. M. \& Ortega, L. (2000). Effectiveness of L2 instruction: A research synthesis and quantitative meta-analysis. Language Learning, 50(3), 417-528. https://doi.org/ 10.1111/0023-8333.00136.

Oxenden, C., Latham-Koeing, C. \& Seligson, P. (2008). American English file (student book 2). Oxford: Oxford University Press. 
Pérez-Hernández, L. (2011). Cognitive tools for successful branding. Applied Linguistics 32 (4), 369-388. https://doi.org/10.1093/applin/amr004

Schintani, N. (2011). A comparative study of the effects of input-based and productionbased instruction on vocabulary acquisition by young EFL learners. Language Teaching Research, 15(2), 137-158. https://doi.org/10.1177/1362168810388692

Schmitt, N. (2008). Instructed second language vocabulary learning. Language Teaching Research, 12(3), 329-363. https://doi.org/10.1177/1362168808089921

Schnotz, W. (2005). An integrated model of text and picture comprehension". In R. E. Mayer (ed.), Cambridge Handbook of Multimedia Learning (pp. 49-69). Cambridge, UK: Cambridge University Press.

Skrzypek, A. \& Singleton, D. (2013). Productive knowledge of English collocations in adult Polish learners: The role of short-term memory. Vigo International Journal of Applied Linguistics, 10, 105-129. Retrieved from http://vialjournal.webs.uvigo.es/pdf/ Vial-2013-Article5.pdf

Sobrino, P. P. (2014). Multimodal cognitive operations in classical music. Vigo International Journal of Applied Linguistics, 11, 137-168. Retrieved from http://vialjournal.webs. uvigo.es/pdf/Vial-2014-Article6.pdf

Song, X., Schnotz, W. \& Juchem-Grundmann, C. (2015). A cognitive linguistic approach to teaching English prepositions. In Schnotz W., Kauertz A., Ludwig H., Müller A., Pretsch J. (eds) Multidisciplinary Research on Teaching and Learning (pp. 109-128). Palgrave Macmillan, London.

Taylor, J. R. (1989). Linguistic categorization: Prototypes in linguistic theory. Oxford: Oxford University Press.

Ticio, E. \& Avram, L. (2015). The acquisition of differential object marking in Spanish and Romanian: semantic scales or semantic features?. Revue Romaine de Linguistique, 4, 383-402.

Tyler, A., Mueller, C. \& Ho, V. (2011). Applying Cognitive Linguistics to Learning the Semantics of English to, for and at: An Experimental Investigation. Vigo International Journal of Applied Linguistics, 8, 181-205.

Vasiljevic, Z. (2011). Using conceptual metaphors and L1 definitions in teaching idioms to non-native speakers. The Journal of Asia TEFL 8(3), 135-160. 